\title{
The Impact of Heat Transfer on Glucose Generation and Degradation with Instant Heating and Slow Heating Technologies
}

\author{
Harun Sarip, Mohd Azemi Mohd Noor, and Karim Allaf
}

\begin{abstract}
The impact of fast and slow heating during non-isothermal hydrolysis stage of crude sago starch was compared between DIC system (direct steam injection) against DAH system (external heating source). Heating process, glucose and glucose degradation products was quantified and modelled after the first order kinetic reaction. Rate constant, $h$ was obtained from a numerical model fitted into kinetic data. $h_{D I C}$ was $45 \mathrm{~min}^{-1}$ and $33 \mathrm{~min}^{-1}$ at $130^{\circ} \mathrm{C}$ and $150^{\circ} \mathrm{C}$ respectively, while $h_{D A H}$ was $0.565 \mathrm{~min}^{-1}$ and $0.725 \mathrm{~min}^{-1}$ at respective temperature. Relative rate $h_{D I C} h_{D A H}$ was 79.7 and 45.5 at respective temperature. Glucose generation rate during non-isothermal stage was $6.0 \mathrm{mg} / \mathrm{s}$ and $1.03 \mathrm{mg} / \mathrm{s}$ for respective DIC and DAH system. Total glucose degradation products at the end of non-isothermal stage were $0.4 \mathrm{mg}$ (DIC) and $20.5 \mathrm{mg}$ (DAH). It is concluded that DIC system having potential as a pre-treatment system to optimize glucose generation while controlling its degradation.
\end{abstract}

Index Terms-Kinetic, glucose, non-isothermal, hydrolysis.

\section{INTRODUCTION}

Enzymatic and chemical hydrolysis are two popular methods for producing sugars from biomass materials. Recent interest in chemical hydrolysis was seen as a viable method as promising means for the sugar process due to the actual increase in cost for enzymatic processes in terms of enzyme cost [1], longer processing time and the requirement to utilize various types of buffer and for its controls during the production [2]. Common process such as acid hydrolysis or thermal treatment produced several types of microorganism inhibitors such as furfural, hydroxymethylfurfural and levulinic acid that needs to be addressed to ensure glucose is suitable for bioprocessing applications [3]-[5]. Two rate constants for conversion of polysaccharides to glucose $\left(k_{l}\right)$ and for conversion of glucose to glucose degradation products $\left(k_{2}\right)$ are available for specific studies [4].

The objective of this work was to understand the effect of fast and slow heating on the start-up formation of glucose degradation products. Non-isothermal region of the heating process that was known to follow the first-order reaction kinetic was selected [4], [6]. Heat-transfer equation was used

Manuscript received May 22, 2015; revised July 10, 2015. This work was supported by UniKL-MARA, and was done in Université de La Rochelle, France.

Harun Sarip and Mohamad Azemi Mohd Noor are with Universiti Kuala Lumpur, Malaysia, based in Chemical Engineering Campus in Melaka, Malaysia (e-mail: harun@unikl.edu.my,drazemi@unikl.edu.my).

Karim Allaf is with Université de La Rochelle, France (e-mail: kallaf@univ-lr-fr). to model the relationship of non-isothermal situation of systems studied. In this work, two systems based on a closed thermal system were studied, known as DIC and DAH system.

DIC process (French: Détente Instantanée Contrôlée (DIC)) or instant controlled pressure drop, is a process involves heating under steam pressure followed by abruptly releasing the pressure towards vacuum [7], [8]. The sudden pressure drop $\left(\delta P / \delta t>2.5 \times 10^{5} \mathrm{~Pa} / \mathrm{s}\right)$ causes quick cooling of the treated material and evaporation inside the bulk of material cause it to blows and breaks cell walls' cavities with potential to induce auto-hydrolysis on polysaccharide's materials into glucose [5].

DAH process or Dilute Acid Hydrolysis process was done using small batch pressure reactors made of stainless steel 316 with screw cap and fitted with Teflon insert. Total volume of DAH reactor was $20 \mathrm{ml}$, while volume use for experiment was $10 \mathrm{ml}$ to have good headspace for steam volume expansion.

The study of the non-isothermal situation of this thermal system was done according to first-order reaction kinetic to investigate and correlate both systems with products from each process. It was known that thermal system is associated with the heat-transfer reaction, and it is affected the hydrolysis of polysaccharides into glucose and further degrade it if not controlled [4]. Model for the increase in product temperature during DIC and DAH process is presented in the following heat transfer equation:

Heat transfer equation:

$$
m C_{p} T=U A T
$$

where $m, C_{p}, T, U$ and $A$ is mass, water heat capacity, temperature, overall heat transfer coefficient and heat transfer area respectively.

For a close thermal system such as DIC reactor or DAH system consists of small stainless steel reactors, the $m$ and $C p$ is constant over the time; the equation can be arranged to reflect only the changes in temperature, $T$ of reaction mixture over time, $t$ in a positive heat transfer from source (steam or hot oil bath) to the reaction mixture inside the system. Heat transfer coefficient $U$, and heat transfer area, $A$ also will become constant in this case [4].

Overall heat transfer is reflected by the temperature gradient only as follows:

$$
\frac{d\left(m C_{p} T\right)}{d t}=U A\left(T_{\text {source }}-T\right)
$$

After integration and solving the constant with 


$$
h=\frac{U A}{m C_{p}}
$$

The final form of heating equation becomes:

$$
T=T_{\text {source }}-\left(T_{\text {source }}-T_{f}\right) \exp ^{-h_{h} t}
$$

where $h_{h}$ : rate constant for heating from bath to reaction mixture, $T_{\text {source }}$ : temperature of steam for DIC or oil bath for dilute acid hydrolysis, $T_{f}$ : temperature of mixture and $t$ : treatment time. Equation (4) was used to determine value for $h$ at each experimental temperature by fitting data obtained from experiment into equation to find $T_{\text {model }}$ through lowest sum of squares of $\left(T_{\text {source }}-T_{\text {model }}\right)$ using solver in Microsoft® Excel [6].

\section{MATERIAL AND METHOD}

\section{A. DIC System and Treatment}

The DIC system was described previously [5], [7], [8], the system composed of three main components; (a) DIC reactor (b) Vacuum system, with an initial vacuum level is maintained at $100 \mathrm{kPa}$ in all trials, and (c) Pneumatic valve system to give an effect of abrupt pressure drop within a treatment vessel by opening valve that connects (a) and (b) in less than $0.2 \mathrm{~s}$. Two thermocouple type $\mathbf{J}$ was attached to the thermocouple connector inside of reactor. One thermocouple probe end was placed inside of material, and the other one was exposed to reactor environments. 10 grams crude sago starch (CSS) was used in each treatment.

Temperature acquisition for DAH system was done with thermocouple Type $\mathrm{J}$ that attached to the screw cap, plug with Teflon from inside. High tension spring was attached to thermocouple probe from outside to ensure system was very tight. Weight of DAH system was recorded before and after each trial. $500 \mathrm{mg}$ DIC treated CSS was added into tube containing $10 \mathrm{ml} 0.08$ molar sulfuric acid and transferred into a hot oil bath previously set at 110,130 or $150^{\circ} \mathrm{C}$. Another thermocouple probe was placed in the oil bath to record its temperature. Fig. 1(a) and (b) shows the configuration used in both system in this study.

Data acquisition was done with data logger Omega HH147U and its data was downloaded into a computer with Temperature Monitor S2 software (version 1.0.16). Data acquisition rate was 10 points/s for DIC system and 1 point/s for DAH study. Accuracy of data was $0.1 \%$ for reading range between -100 to $1000^{\circ} \mathrm{C}$ according to manufacturer specifications. Further processing was done in Microsoft ${ }^{\circledR}$ Excel fitting to Equation (4). Data logger was calibrated according to manufacturer specification.

\section{B. Glucose Determination}

Determination of glucose and glucose degradation products was done with Agilent 1100 HPLC system consist of G1311A Quaternary Pump, G1362A RI Detector, G1313A Autosampler, G1322A Vacuum Degasser, Solvent Module and controlled by Chemstation software. ICE-COREGEL $87 \mathrm{H} 3$ (Transgenomic) column was used at $35^{\circ} \mathrm{C}$ to separate glucose and certain organic acid in solution. Mobile phase was a dilute sulfuric acid $(5 \mathrm{mM})$ in deionised water at a flow rate of $0.5 \mathrm{ml} / \mathrm{min} .10 \mu \mathrm{l}$ of sample and standards at different concentration are injected into the system for analysis and quantification.

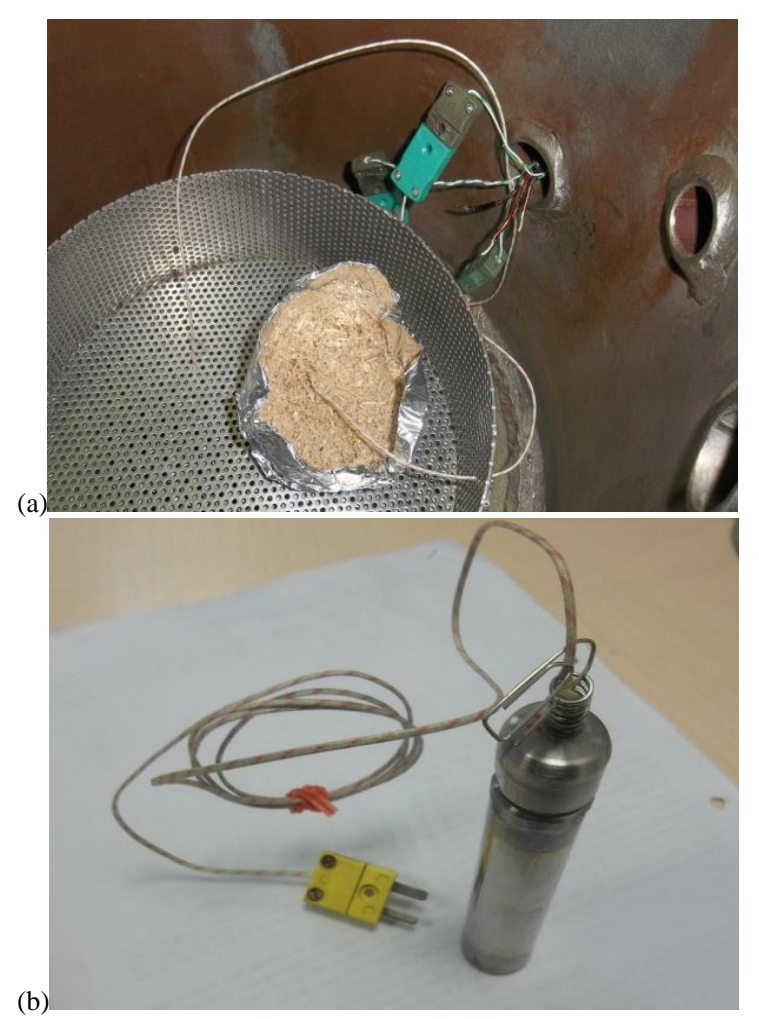

Fig. 1. (a) Two thermocouple probes with one attached to the product and the other one exposed to DIC reactor environment (b) Stainless steel reactor in non-isothermal study with thermocouple probe.

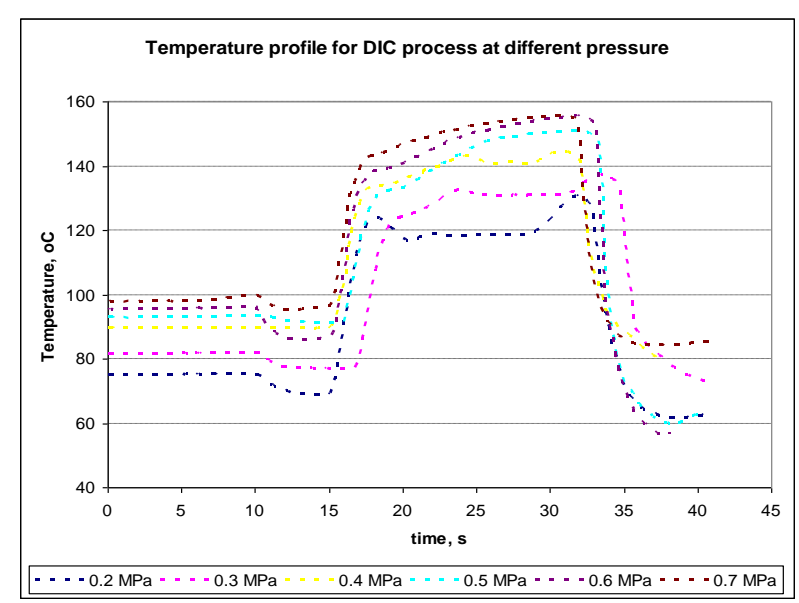

Fig. 2. Profile of the non-isothermal plot for product temperature during DIC cycles at several saturated steam pressure. Data acquisition was done at several starting temperature.

\section{RESULT AND DISCUSSION}

Profile of the non-isothermal plot of several DIC treatment cycles is presented in Fig. 2. Its corresponding numerical model was calculated and modelled after first kinetic reaction order and respective $h_{h}$ constant at each steam pressure was obtained, with initial condition of $28^{\circ} \mathrm{C}$ for all models as presented in Fig. 3(a). Similar treatment and analysis were done for DAH system. Results for analysis of rate constant were presented in Table I and Table II. Modelled data for both DIC and DAH systems were presented in Fig. 3(a) and (b). 
Value of rate constant for heating in Table I and Table II was useful to describe the non-isothermal regime during start-up of the dilute acid hydrolysis kinetic. About 5 minutes was required to raise the product temperature towards reaction temperature in DAH system, while only about 5 seconds was required in DIC system. Relative rate constant for heating for DIC and DAH as in Table III shows that DIC system was about 45 to 80 times higher than DAH system depending on final temperature of the system.

\begin{tabular}{|c|c|c|c|}
\hline $\mathrm{T},{ }^{\circ} \mathrm{C}$ (planned) & $\mathrm{T},{ }^{\circ} \mathrm{C}$ (actual data obtained) & $h_{D A H}, \mathrm{~s}^{-1}$ & $h_{D A H}, \min ^{-1}$ \\
\hline 110 & 111 & 0.00780 & 0.4680 \\
\hline 130 & 132 & 0.00942 & 0.5650 \\
\hline 150 & 153 & 0.01208 & 0.7250 \\
\hline
\end{tabular}

TABLE III: DIC TREATMENT RATE CONSTANT FOR HEATING WITH UNIT IN

\begin{tabular}{llll}
\multicolumn{3}{c}{$\mathrm{S}^{-1} \mathrm{AND} \mathrm{MIN}^{-1}$} \\
\hline $\mathrm{P}, \mathrm{MPa}$ & $\mathrm{T},{ }^{\circ} \mathrm{C}$ & $h_{D I C}, \mathrm{~s}^{-1}$ & $h_{D I C}, \mathrm{~min}^{-1}$ \\
0.2 & 120.2 & 0.8050 & 48.300 \\
0.3 & 133.5 & 0.7505 & 45.030 \\
0.4 & 143.6 & 0.5505 & 33.030 \\
0.5 & 151.8 & 0.5503 & 33.018 \\
0.6 & 158.8 & 0.5504 & 33.022 \\
0.7 & 164.9 & 0.5495 & 32.972 \\
\hline
\end{tabular}

TABLE III: VALUE OF RELATIVE RATE CONSTANT FOR HEATING AT 110, 130 AND $150^{\circ} \mathrm{C}$ FOR BOTH DIC AND DAH SYSTEMS

\begin{tabular}{llll}
\hline Temperature, $\mathrm{C}$ & $\begin{array}{l}\text { DIC system, } \\
h_{D I C}, \mathrm{~min}^{-1}\end{array}$ & $\begin{array}{l}\text { DAH system, } \\
h_{D A H}, \mathrm{~min}^{-1}\end{array}$ & $\begin{array}{l}\text { Relative rate of } \\
\text { heating }: h_{D I C} / h_{D A H}\end{array}$ \\
\hline 110 & $\mathrm{n} / \mathrm{a}$ & 0.468 & $\mathrm{n} / \mathrm{a}$ \\
130 & 45.030 & 0.565 & 79.7 \\
150 & 33.018 & 0.725 & 45.5 \\
\hline
\end{tabular}

Information obtained from this study offers an insight into the difference in heat transfer of both DIC and DAH systems, and it can be associated with the requirement of rate constant $k_{1}$ and $k_{2}$ (in which $k_{1}>>k_{2}$ was required for maximum hydrolysis of polysaccharides into glucose). Fast hydrolysis kinetic operation during conversion of polysaccharides into glucose with minimum glucose degradation was required in this study. In this study, DIC system was found to offer faster reaction compared to DAH system.

To compare the effect of approximate glucose obtained from the existing process, the following Table IV is presented and its calculated data based on glucose generated at an initial isothermal time for respective system. DIC system was found to give higher glucose rate for each CSS amount, $6.0 \mathrm{~g} / \mathrm{s}$ for each gram CSS, while DAH system only $1.03 \mathrm{~g} / \mathrm{s}$ for each gram CSS. Based on that, DIC rate of conversion was 5.8 times much higher than using DAH process. DAH system in this study was using low DIC severity treated materials as specified in Table IV. If treatment was using crude sago starch with no DIC pre-treatment, a much lower glucose amount can be expected.

Relative rate for the conversion based on glucose conversion in Table IV was found to be less than the relative rate of heating in Table III, which is normal if we take into consideration for two steps conversion of polysaccharides into glucose [4]. The consecutive reaction steps will normally require the concentration of substrate to achieve a certain level before it started. So with some limitation on time and acid concentration the rate for that particular temperature will be affected. Moreover, DIC and DAH were involved with mass conversion as compared to non-isothermal study only involved with temperature.

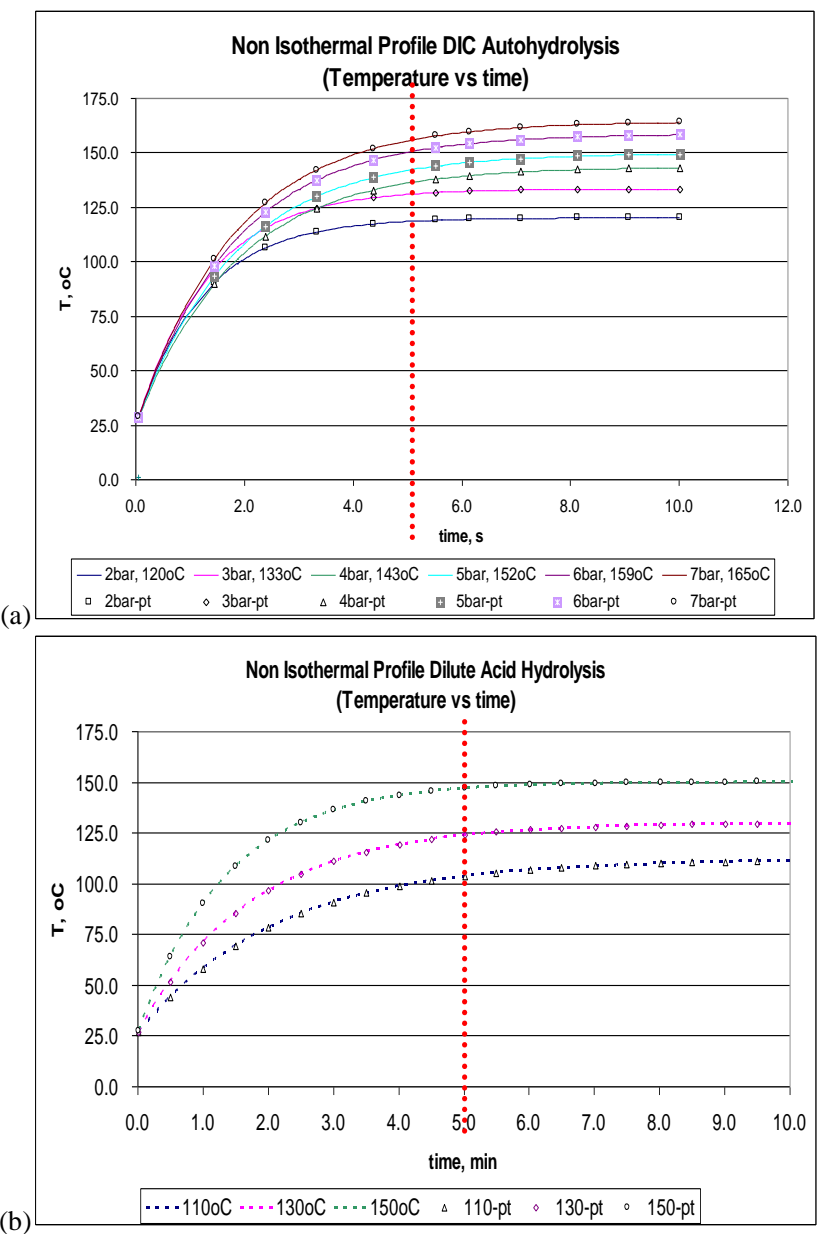

Fig. 3. Model plot of heating for (a) DIC and (b) DAH, $h$ value was obtained from experimental data fitting with calculated model using Equation (4).

Red line indicated time required to surpass the non-isothermal temperature.

TABLE IV: VALUE OF GLUCOSE FOR DIC AND DAH SYSTEM AT THE END OF NON-ISOTHERMAL TIME. RATE OF GLUCOSE CONVERSION WAS CALCUlATED TO ASSIST FOR COMPARING OF BOTH SYSTEMS AT $150^{\circ} \mathrm{C}$ System Time at end Glucose Glucose Glucose source \begin{tabular}{lll} 
non-isothermal & $\begin{array}{l}\mathrm{mg} / \mathrm{g} \\
\mathrm{CSS}\end{array}$ & $\begin{array}{l}\text { rate, } \\
\mathrm{mg} / \mathrm{g} \mathrm{s}\end{array}$ \\
\hline $\mathrm{DIC}$ & $5 \mathrm{~s}$
\end{tabular}

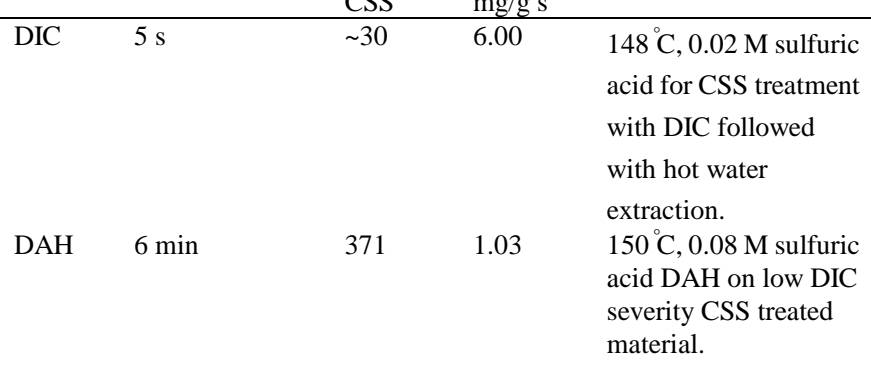

In previous comparison CSS study utilizing hydrolysis kinetic model [5], it was shown that total glucose degradation product at a level-off temperature of $150^{\circ} \mathrm{C}$ from kinetic models of respective system was about $0.4 \mathrm{mg}$ (DIC) and 20.5 mg (DAH) which was contributed by a fast reaction time for DIC system compared to DAH systems [5]. This finding further support DIC technology as a potential biomass pre-treatment system. 


\section{CONCLUSION}

In this paper, a comparison study between DIC and DAH system was presented that related to the function of heat transfer and glucose conversion rate of two systems. It was found that DIC system offers high heat transfer rate and glucose conversion rate at a magnitude of nearly 80 times and 5 times higher than DAH system for both functions being studied respectively. This finding was important for the development of a process for polysaccharide's hydrolysis into glucose with very minimum glucose degradation using DIC technology after comparison with full kinetic model. Practical estimation of heat loss for better system efficiency can be further calculated. Control and efficiency of a thermal system can be pre-estimated using the heat-transfer coefficient for a very heat sensitive process or materials, making the process are in control.

\section{ACKNOWLEDGMENT}

This study was financially supported by MARA and Universiti Kuala Lumpur. All experiment was conducted at LaSIE, Université de La Rochelle.

\section{REFERENCES}

[1] D. Klein-Marcuschamer, P. Oleskowicz-Popiel, B. A. Simmons, and H. W. Blanch, "The challenge of enzyme cost in the production of lignocellulosic biofuels," Biotechnology and Bioengineering, vol. 109, no. 4, pp. 1083-1087, 2012.
[2] N. Mosier, C. Wyman, B. Dale, R. Elander, Y. Y. Lee, M. Holtzapple, and M. Ladisch, "Features of promising technologies for pretreatment of lignocellulosic biomass," Bioresource Technology, vol. 96, no. 6 , pp. 673-686, 2005.

[3] J. F. Saeman, "Kinetics of wood saccharification - hydrolysis of cellulose and decomposition of sugars in dilute acid at high temperature," Industrial \& Engineering Chemistry, vol. 37, pp. 43-52, 1945.

[4] B. Girisuta, L. P. B. M. Janssen, and H. J. Heeres, "Kinetic study on the acid-catalyzed hydrolysis of cellulose to Levulinic acid," Industrial \& Engineering Chemistry Research, vol. 46, no. 6, pp. 1696-1708, 2007.

[5] H. Sarip, K. Allaf, and M. A. M. Noor, "Pure cellulose conversion to glucose with instant pressure drop (DIC) technology," International Journal of Engineering and Technology, vol. 8, no. 2, pp. 36-41, 2011

[6] K. A. Connors, Chemical kinetics: The Study of Reaction Rates in Solution, VCH, 1990.

[7] C. Besombes, B. Berka-Zougali, and K. Allaf, "Instant controlled pressure drop extraction of lavandin essential oils: Fundamentals and experimental studies," Journal of Chromatography A, vol. 1217, no. 44, pp. 6807-6815, 2010.

[8] T. Allaf and K. Allaf, Instant Controlled Pressure Drop (D.I.C.) in Food Processing, New York, NY: Springer New York, 2014.

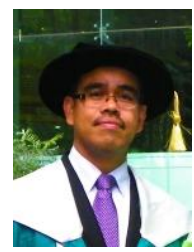

Harun Sarip obtained his national diploma of doctor in engineering from Université de La Rochelle, France in 2012. Presently, he is a senior lecturer with Universiti Kuala Lumpur, Malaysia. His research interest is in conversion of biomass waste into polysaccharides and glucose and controlling its degradation. He is a member of International Society of Pharmaceutical Engineer. 